\title{
PARADOXOS DO CAPITALISMO E TRABALHO EM CALL CENTERS: Brasil, Portugal e Cabo Verde
}

\author{
Cinara L. Rosenfield
}

\section{INTRODUÇÃO}

O objetivo deste artigo é compreender o contexto no qual se insere o trabalho na chamada sociedade da informação e as diferentes formas de trabalho que nela se desenvolvem, em especial, o teletrabalho em call centers. Diante de um novo paradigma tecnológico, característico da era da informação, trata-se de analisar as diferentes configurações do trabalho. Interessa-nos aqui investigar e analisar o trabalho ligado às Tecnologias de Informação e Comunicação (TICs). Por um lado, essas tecnologias, por referirem-se a atividades de natureza compreensiva e imaterial, traduziriam uma redução da amplitude da divisão do trabalho entre os que concebem e os que executam; mas, por outro, a realidade do trabalho ligado às TICs mostra-se complexa e ambígua, pois há indícios de uma manutenção da divisão, ou mesmo a combinação entre trabalhos "inteligentes" e trabalhos controlados e repetitivos. O trabalho em call centers pare-

* Professor-Doutor do Departamento de Sociologia e do Programa de Pós-Graduação de Sociologia da Universidade Federal do Rio Grande do Sul. Av. Bento Gonçalves, 9500 - Sala 103 (IFCH) - Campus do Vale. Cep: 91509900 Porto Alegre -RS - Brasil. rosenfield@uol.com.br ce condensar essas ambigüidades de um trabalho informacional com alto controle, o que o colocaria entre as esperanças do pós-taylorismo e os temores do neo-taylorismo.

A Teoria Crítica de Axel Honneth (2003a, 2003b, 2006) permite-nos pensar a experiência do trabalho no seio daquilo que o autor intitula "paradoxos do capitalismo". O significado do trabalho, em sua dimensão social, ganha força ao ser demonstrado que o "novo capitalismo" logra produzir progresso moral, baseado nos legados do Estado Social e do modelo taylorista e fordista de trabalho, e, simultaneamente, produz o seu contrário, ao erodir o alcance emancipador dessas normas e valores. Os paradoxos do capitalismo em rede encontram no trabalho em call centers a produção exemplar dessa contradição. Este artigo analisa o trabalho em call centers em três países de língua portuguesa: Brasil, Portugal e Cabo Verde.

\section{OS PARADOXOS DO CAPITALISMO}

Nas duas últimas décadas, foi possível constatar mudanças importantes na organização do tra- 
balho, mudanças essas que apontam para exigências de mobilização subjetiva dos trabalhadores, a fim de atingirem a correta execução de suas responsabilidades. A autonomia do trabalhador passou a ser a norma para a correta execução do trabalho, o que vem a constituir um quadro de autonomia outorgada. A autonomia é outorgada na medida em que ela é "concedida" aos trabalhadores, mas se constitui, ao mesmo tempo, em uma ordem a ser obedecida (Rosenfield, 2003, 2004). A antiga organização do trabalho taylorista ou fordista viu-se diante da necessidade de renovação, a fim de dar respostas a outro tipo de exigência: para garantir qualidade e competitividade, agora em escala inédita, o trabalhador deve integrar a compreensão da tarefa, de maneira a possibilitar um trabalho de concertação e de troca de informações e saberes não só no momento de concepção, mas também no de sua execução. Essa seria a nova face da dominação do capital: é mister que o trabalhador se identifique pessoalmente, que se mobilize subjetivamente, que lance mão de suas capacidades psíquicas e relacionais para bem executar seu trabalho.

No nosso entendimento, o trabalho tem um papel insubstituível no processo de elaboração da imagem de si, e a cooperação resultante da integração pelo trabalho engaja o ator no futuro coletivo. O trabalho participa na construção do elo social, uma vez que ele funda a autonomia social das pessoas. Para Perret (1988), é o caráter especificamente humano do trabalho-e, portanto, mais nobre-que serve de competência insubstituível, a saber: (1) a capacidade de interpretar uma informação em função da totalidade de elementos do contexto; (2) a imaginação, a capacidade de inventar novos mundos de inacreditável complexidade; e (3) a capacidade de entrar em comunicação e em simpatia com seus semelhantes, de conquistar a confiança dos outros. Mas o autor salienta que o trabalho humano permanecerá também nas zonas escuras dos sistemas mais performáticos: sempre existirá o trabalho "sujo" e manual a fazer.

No entanto, esse elo social prometido pelo trabalho tem um duplo movimento: de integração, quando a ênfase é colocada sobre a mobilização e o engajamento dos trabalhadores; de precariedade, quando se trata de redução de custos e de ajustamento da mão-de-obra às novas exigências de produção.

Na empresa pós-fordista, segundo Gorz (1988), o trabalho imediato de produção é somente o resultado de uma aplicação material de um trabalho imaterial que supõe a reflexão, a concertação de saberes e de observações, a troca de informações. Quando esse processo parecia anunciar a reapropriação do trabalho pelos trabalhadores, a transformação do trabalho em um bem cuja possessão exige sacrifícios e a transformação do emprego em um privilégio culminam em uma sujeição da própria pessoa do trabalhador. Assim, para o autor, entender a autonomia no trabalho, preconizada pela empresa pós-fordista, como um exercício de autonomia do trabalhador, é um "delírio teoricista".

A teoria crítica de Axel Honneth parece trazer uma notável contribuição ao processo de entendimento do paradoxo, presente nessa fase do capitalismo, entre uma concepção normativa da emancipação e os potenciais de destruição e negatividade desses elementos de emancipação.

Olivier Voirol, no prefácio ao livro de Honneth (2006), divide a obra desse autor em três grandes temas, aos quais o autor se dedica de maneira evolutiva, guardando, no entanto, um questionamento fundamental próprio à teoria crítica: "como o quadro categorial de uma análise que, ao mesmo tempo, seja capaz de contemplar tanto as estruturas de dominação social como também os processos sociais de sua superação prática deve ser elaborada?" (Honneth apud Saavedra, 2007). O primeiro deles é consagrado ao estudo das "patologias do social", o segundo à "teoria do reconhecimento" e o terceiro aos "paradoxos do capitalismo".

O tema das "patologias do social” remete à noção de uma sociedade "normal" como aquela que garante aos seus membros a realização individual. Dessa maneira, estaria assegurada aos sujeitos uma "boa vida", ou vida bem sucedida, definida segundo um julgamento normativo. As "patologias sociais" são deficiências sociais que resul- 
tam em atentados às condições sociais de autorealização individual.

O segundo tema consagra-se a teoria do reconhecimento (Taylor, 1997; Honneth, 2003a, 2003b; Fraser, 2001, 2003). Essa teoria traz uma importante contribuição à compreensão da dimensão social dos processos identitários e de construção da autonomia individual. Seguindo a argumentação de Axel Honneth (2003b) - e restringindo-se a esse autor -, seriam três as esferas do reconhecimento: dedicação emotiva, respeito cognitivo e estima social. Para os indivíduos poderem dispor de suas autonomias individuais, é preciso que socialmente sejam reconhecidas suas necessidades, sua igualdade legal e (ou) suas contribuições sociais. O que se reverte na possibilidade de o sujeito realizar sua autonomia individual ao desenvolver uma auto-relação marcada, respectivamente, pela autoconfiança, autorespeito e auto-estima.

Tal situação implica, por um lado, um processo de individualização, na medida em que aumentam as chances de expressão, legitimação e reconhecimento de diferentes facetas da personalidade do sujeito, embora signifique igualmente, por outro, um processo de inclusão social, por inserir o sujeito no círculo igualitário composto de todos os membros da sociedade. Ambos os processos indicam possibilidades de aumento do reconhecimento social. A integração social dá-se através de relações de reconhecimento que confirmam as diversas facetas da personalidade dos sujeitos, e eles se tornam membros da sociedade (inclusão social):

... o progresso nas condições de reconhecimento social surge nas duas dimensões de individualização e inclusão social: ou novas partes da personalidade são abertas ao reconhecimento mútuo, então surge a extensão da individualidade social confirmada; ou mais pessoas são incluídas nas relações existentes de reconhecimento, de forma que o círculo de sujeitos que reconhecem uns aos outros cresce (Honneth, 2003b, p.186). ${ }^{1}$

A auto-realização individual só encontra condições asseguradas socialmente pela experiên-

\footnotetext{
${ }^{1}$ Todas as traduções de referências bibliográficas em língua estrangeira são traduções livres da autora deste artigo.
}

cia do reconhecimento intersubjetivo da autonomia individual, das necessidades específicas e das capacidades particulares. A teoria do reconhecimento social permite, assim, alçar os processos identitários a uma dimensão social, convertendo as questões da autonomia individual em questões de natureza social. Honneth sustenta que aquilo que os sujeitos esperam da sociedade é, acima de tudo, reconhecimento de suas demandas identitárias. A experiência de injustiça social dáse quando aspectos da personalidade - que se acredita possuirem direito ao reconhecimento - são desrespeitados. A autonomia individual tem por "objetivo" a possibilidade de uma "formação identitária". Assim, a igualdade entre os sujeitos se materializa na formação identitária pessoal, que é dependente das relações de reconhecimento mútuo. Possibilitar o desenvolvimento individual e a auto-realização dos sujeitos constitui o verdadeiro objetivo (ou demanda) de um tratamento igualitário entre os sujeitos nas nossas sociedades.

O terceiro momento da obra pode ser caracterizado pelo tema "paradoxos do capitalismo". Nele, Honneth desenvolve a tese de que o novo capitalismo (também nomeado pelo autor de capitalismo em rede, capitalismo flexível e capitalismo por projetos), surgido com a revolução neoliberal, segundo as palavras do autor, conseguiu mobilizar novos recursos motivacionais a partir da herança do Estado Social do pós-guerra e do modelo taylorista e fordista de trabalho - heranças essas que significaram um notável progresso moral para a humanidade em termos de atributos desejáveis ou obrigatórios das relações entre os sujeitos -, ao “(...) manter em condições socioeconômicas novas as aquisições institucionalizadas durante o período social-democrata, ou transpô-las sob uma forma modernizada." (Honneth, 2006, p.286). Quais são essas aquisições institucionalizadas? São quatro (e aqui vemos uma evolução em relação às três esferas do reconhecimento, a saber, o amor, o direito e a solidariedade): a) o individualismo, como representação dominante de si; b) a idéia de igualdade universal, como forma de regulação jurídica; c) a idéia de performance (Leistung), como princípio 
de atribuição de status ou de posição social; d) a idéia de amor romântico, como avanço emocional dos elementos institucionalizados da vida cotidiana (Cf. Honneth, 2006, p.277).

O individualismo se manifesta como possibilidade de o sujeito realizar experimentações da própria autonomia ou de facetas de sua autenticidade, em busca de realização de si.

A igualdade universal significa proteção à autonomia jurídica de todos os membros da sociedade, o que viabiliza poder exigir ser tratado como igual e reivindicar seu pertencimento social. Traduz-se em novos direitos sociais e proteção das liberdades para o desenvolvimento individual da autonomia, além da interdição às discriminações relativas a práticas culturais ou sexuais (direitos subjetivos). Os direitos objetivos também se estendem sob a forma de uma generalização da igualdade perante a lei (como, por exemplo, os estrangeiros e as minorias).

A noção de performance remete a "poder fazer valer as implicações normativas do princípio moderno de performance, sublinhando o valor efetivo de suas contribuições à reprodução da sociedade sob forma de um trabalho, a fim de obter uma maior estima social e a compensação material que a acompanha” (Honneth, 2006, p.278). Assim, há uma multiplicação das possibilidades de cada um participar com sucesso da concorrência de performances (através do aumento da escolaridade e do fim das barreiras sociais para mobilidade, por exemplo), dispondo do direito a um trabalho digno, que se traduza numa contribuição e num reconhecimento social (par contribuição-retribuição).

A noção de amor romântico possibilita a liberação da relação íntima dos controles exteriores de tipo social ou econômico. As relações íntimas se estabelecem em função do valor dos sentimentos, de maneira que passam a valer socialmente desejos e necessidades que até então não eram reconhecidos nas práticas institucionalizadas dessas relações.

A tese sustentada por Honneth é de que essas aquisições institucionalizadas (normas e valores) - esses ganhos morais legados da era social- democrata do pós-guerra - são instrumentalizadas pelo capitalismo flexível, no sentido de que ele tem sucesso em "guardá-las", ao mesmo tempo em que logra erodir seu caráter emancipador. No entanto, essa contradição não é percebida como atrelada ao capitalismo, pois os sujeitos "tornaramse” responsáveis por seus destinos e empresários de si mesmos, tornando-se, assim, aparentemente autônomos em relação às imposições do sistema. Esse é o paradoxo central do capitalismo. O termo "paradoxo" deve se entendido como "uma explicação de uma estrutura contraditória específica”, ou seja, "uma contradição é paradoxal quando, através da concretização pretendida de uma intenção, se reduz justamente a probabilidade de se ver essa intenção se concretizar" (Honneth, 2006, p.286).

Assim, com a revolução neoliberal, os modelos de significação do individualismo, do direito, da performance e do amor se transformam de uma maneira "paradoxal", uma vez que: a) se misturam seus momentos positivos e negativos, as melhorias e as degradações; b) o capitalismo se tornou "ético" e concretiza novas justificativas para as desigualdades, ao se referir a um vocabulário de autodescrição normativa (por exemplo, o sujeito, no trabalho, deve vivenciar sua autonomia e sua autenticidade); c) o modelo de contradições "paradoxais" renuncia a uma reconstrução dos conflitos inspirada na luta de classes (Honneth, 2006, p.288).

Seguindo a tese de Boltanski e Chiapello (1999) a respeito do capitalismo "por projetos", Honneth sustenta que as pessoas valorizadas são aquelas que se disponibilizam a engajar-se pessoalmente aos novos projetos, que demonstram grande flexibilidade, que dispõem de boas competências relacionais para se integrarem em redes e que agem de maneira autônoma, mostrando-se dignas de confiança. O trabalhador passa a ser seu próprio empreendedor, ao dispor de suas próprias competências e seus recursos emocionais a serviço de projetos individualizados.

Os paradoxos do capitalismo mostram seus efeitos nas quatro esferas dos avanços morais. O individualismo, entendido como autonomia e au- 
tenticidade, reverteu-se em seu contrário, na medida em que: a) integrou exigências de qualificação e comportamento como forma de inserção no sistema econômico; b) as fronteiras entre a esfera privada e a esfera pública profissional embaralharam-se (vide a mobilização de recursos e competências comunicacionais e emocionais no mundo do trabalho); c) a racionalidade econômica foi colonizada pelo mundo da vida (Honneth, 2006, p.291). Tornou-se difícil aos sujeitos fazerem a diferença entre o que remete às relações intersubjetivas e o que remete à lógica instrumental.

A extensão dos direitos de participação política e das liberdades civis significa maior autonomia individual e a interdição de formas de discriminação de comportamentos culturais e sexuais. Ora, a própria instituição de ajuda social pelo Estado é uma confissão de desigualdades sociais prévias que necessitam ser atenuadas e uma forma de conferir maior poder de participação ao sujeito que necessita de ajuda social. Cada vez mais essas formas de ajuda vêm sofrendo a crítica de seu formato paternalista, para reverter em seu contrário, a saber, a responsabilização pessoal do destino de cada um. Todavia o discurso da responsabilidade pessoal ignora o quanto ela é dependente de condições internas e externas de sua produção social. A responsabilidade individual tomada em si mesma, independentemente dessas condições, transforma-se num "imperativo" de movimento paradoxal, dado que se refere a condições de produção de uma sociedade cada vez mais complexa, na qual os sujeitos não podem, na maioria dos aspectos de sua existência, assumir responsabilidades no sentido pleno do termo. Quando fracassa na plena e exitosa execução de sua "responsabilidade individual", o sujeito vivencia o fracasso daquele que não está à altura das exigências postas e não daquele que enfrenta regras impróprias ou que foi lesado em seus direitos (Ehrenberg, 1995 apud Honneth, 2006).

Se a noção de performance como emancipação entende o sucesso com base em esforços próprios e possibilita maior participação com chances iguais, o "capitalismo por projeto" acaba por não deixar claro aos sujeitos se as relações de trabalho se realizam sobre uma base objetiva ou sobre a base da afeição. Há dificuldade de objetivar as competências requeridas, tais como ser flexível, autônomo, de confiança, relacional, o que remete à impossibilidade de os sujeitos se assegurarem quanto ao verdadeiro valor de suas contribuições e performances. O discurso cultua uma emancipação e uma participação que, de fato, não existem.

Por último, o amor apresenta-se imerso no discurso do amor romântico, da autenticidade, das relações íntimas "puras", ou seja, isentas de cálculo de utilidade, mas, ao mesmo tempo, também passível de objetivação através de uma comercialização de bens que simbolizam afeto (do diamante à margarina, cuja tradicional propaganda remete ao café da manhã de uma família feliz). Também o amor sofre a pressão da indefinição das fronteiras do trabalho, pois há cada vez mais exigências maiores de tempo a consagrar ao trabalho, de mobilidade, de responsabilização pessoal e engajamento emocional.

O trabalho aparece, assim, imerso na contradição específica do capitalismo flexível, ao verse diante do paradoxo intransponível entre autonomia e subordinação. O trabalho informacional em call centers (ou centrais de atendimento) é emblemático desse movimento, que busca associar competências relacionais e comunicacionais à subordinação a regras e normas inflexíveis de como atingir metas e objetivos definidos de maneira heterônoma, como veremos a seguir.

\section{O TRABALHO EM CALL CENTERS}

Os call centers ${ }^{2}$ seriam exemplares de um trabalho informacional com alto controle, o que os

${ }^{2}$ Call centers não são uniformes. A priori, não podemos tratá-los como um conjunto homogêneo, pois, além do uso de computador e de tecnologias de comunicação, há outras variáveis, como tamanho, integração ao setor industrial ou de serviços, a complexidade das ações a serem realizadas, a duração média da chamada, a natureza da operação (inbound receptivo, outbound ativo, ou combinada), o estilo do management (Bain; Taylor, 2000, v.15). Como são aqui analisados sob a ótica do trabalho informacional de alto controle, assalariado e repetitivo, não nos deteremos nas especificidades dos call centers. 
colocaria no seio de duas correntes contraditórias, a do pós-taylorismo e a do neo-taylorismo. O neotaylorismo se faria notar por submissão ao tempo e à estrutura dos softwares, controle racional do tempo e do trabalho por meio da informática, produtividade máxima em detrimento das boas condições físicas e psicológicas dos trabalhadores (ver Lesão por Esforços Repetitivos, LER, e depressão). Seria um trabalho "sem refúgio". A priori, o trabalho prescrito é o trabalho real e controlado, embora formas de burlar o controle sejam desenvolvidas (Rosenfield, 2008, prelo).

A organização do trabalho em call centers poderia se enquadrar nas características do póstaylorismo pela demanda de mobilização subjetiva e de competências relacionais e comunicacionais, assim como por analogia à injunção paradoxal, ${ }^{3}$ embora haja mudanças no seu conteúdo: no póstaylorismo industrial a injunção paradoxal é ser autônomo e trabalhar dentro das normas, ou seja, em nome de tornar-se sujeito, o trabalhador é enviado à sua condição histórica de objeto e, em nome de maior liberdade, legitima-se um imperativo de mobilização subjetiva (Rosenfield, 2003b). Já no pós-taylorismo informacional, e especificamente em call centers, trata-se de garantir a qualidade e a satisfação do cliente, ser gentil, educado, responder com bom-humor, em um ritmo acelerado e em bem pouco tempo, fazendo o cliente crer que é um bom negócio, mesmo quando o próprio operador sabe que não é (como vender um plano de provedor de internet para quem não tem computador). O stress dos teleoperadores é referente à ausência de meios materiais e pessoais para agir frente aos constrangimentos e responder a exigências e objetivos fixados de maneira heterônoma.

Se, em algumas dimensões de análise, é possível distinguir claramente elementos ou do neotaylorismo ou do pós-taylorismo, em outras, os

${ }^{3}$ Trata-se de uma injunção paradoxal justamente por ser uma ordem impossível de ser obedecida, ou seja, a sua simples obediência acarreta a infração. Tal qual a ordem dada por uma mãe: "você tem o dever de me amar espontaneamente". Se ele a ama espontaneamente, então não está cumprindo o seu dever. O mesmo se verifica caso não ame, o que acarreta uma situação sem saída (Palmade, 1993). elementos se confundem, e sua classificação deixa de ser simples e unívoca: (1) há somente um parcelamento relativo das tarefas, ou seja, a situação de trabalho é "completa", embora ela possa ser recortada e seqüenciada; 2) há setores com trabalho repetitivo (registros diversos, informações), onde os trabalhadores são facilmente substituíveis; mas há setores com trabalho mais autônomo e interativo com o cliente (venda, retenção), onde as competências são mais valorizadas e os trabalhadores menos facilmente substituíveis; 3) é possível verificar uma supervisão rígida pela hierarquia, mas combinada com uma tripla relação: assalariado, hierarquia e cliente (ou usuário), ou seja, de um lado, vemos a tradicional relação entre chefe e subordinado e, de outro, essa relação ganha um outro pólo, que pode mesmo se sobrepor à relação entre chefe e subordinado.

A especificidade do trabalho em call centers seria o de conjugar a herança taylorista ao trabalho informacional e à demanda de mobilização subjetiva (Rosenfield, 2008, prelo). O legado taylorista é identificável através de: a) os tempos são cronometrados nos segundos (inclusive as pau$\operatorname{sas}^{4} \mathrm{e}$ a produtividade), até mesmo com muito mais fineza e precisão do que era possível no trabalho taylorista; b) há um forte controle dos movimentos e gestos (o atendente fica preso ao posto de atendimento pelo head phone ou head set, e seu escopo de movimentação restringe-se ao alcance do fio); c) o próprio processo de trabalho é constantemente monitorado e controlado (através das gravações das ligações, da supervisão em tempo real, das auditorias, além do controle do volume de vendas em tempo real, de maneira a induzir a vender mais para atingir as metas); d) há uma importante rotatividade de operadores; e) a orga-

${ }^{4}$ Num regime de seis horas de trabalho, no Brasil, o operador tem direito a uma pausa-lanche de 15 minutos e outra, intitulada particular, de cinco minutos, que pode ser usada conforme a demanda do trabalhador, mas mediante licença da supervisão. Com uma maioria de trabalhadoras (em todos os países estudados), essa pausa é usada normalmente para o uso do sanitário. Foi-nos relatado o caso de uma operadora ter urinado no posto de atendimento, por não ter obtido licença para a pausa, depois de reiterados pedidos, e ainda o fato de algumas operadoras estarem utilizando fraldas durante o trabalho, para evitar tais situações. 
nização do trabalho em postos individualizados de atendimento impõe a individualização do trabalho, de maneira que os operadores devem se remeter sempre à supervisão e nunca aos pares.

Já a demanda por competências comunicacionais e relacionais se realiza através de uma combinação particular entre "comunicação" e "acesso à informação", só possível de se concretizar através da pessoa do operador, em uma ação "viva" de comunicação (Zarifian, 2002). Essa combinação fica clara através: a) da autonomia real exercitada na interação com o cliente, na diversidade, na variabilidade de cada "caso" atendido (a troca interpessoal é uma das raras fontes de autonomia e reconhecimento para os teleoperadores - daí a dificuldade de suportar ofensas e xingamentos); b) do fato de a subjetividade e as emoções do operador desempenharem um papel importante na interação com o cliente (tanto que, quando destratados pelo cliente, os operadores se sentem pessoalmente atingidos, o que se torna fonte de stress); c) da inventividade e flexibilidade utilizada para vender ("ouvir" o cliente, já que se atendem pessoas de várias partes do país e mesmo de fora dele, como no caso do call center offshore ${ }^{5}$ ); d) de experimentar a satisfação do trabalho útil a alguém, ao flexibilizar o script de atendimento e adaptá-lo àquele cliente, na troca interpessoal (satisfação da interação pessoal, reconhecer um sujeito do outro lado da linha e ser reconhecido também como tal), como demonstra o extrato abaixo.

Tu não vai falar com uma pessoa lá de Candeias, no interior da Bahia, dos termos técnicos do cartão, não, tu só vai dizer que ele vai poder usar num supermercado, na farmaciazinha, se ele precisar dum remédio e não tiver dinheiro. Tu tem que saber como falar com as pessoas. Eu, pelo menos, eu cuido muito bem a maneira de falar. Tem uma maneira de falar aquilo. É que nem aqui no interior do Rio Grande do Sul, como é que tu vai vender lá pruma... lá pra Carlos Barbosa, lá pra não sei onde, falando em Shopping, como? Não tem! Tu vai ter que botar no imaginário dele que ele pode precisar usar no posto de

${ }^{5}$ Empresas remotas ou offshore são call-centers ou teleserviços, através dos quais empresas européias e americanas instalam os seus escritórios-satélites ou subcontratam empresas de teleserviços de outras zonas do globo, com mão-de-obra mais barata, pondo em prática o chamado teletrabalho offshore. gasolina, que um posto de gasolina é automático. Tu tem carro, pro posto de gasolina, sabe? Então, tu tem que viver o mundo dele (operadora, 31 anos, 3 anos na ocupação, Brasil).

As contradições advindas de um trabalho altamente controlado, que demanda investimento pessoal, são, portanto, claras. As fronteiras entre as facetas de natureza subjetiva e as de natureza instrumental se confundem, e os paradoxos são intransponíveis, pois convivem sem solução. Aspectos positivos e negativos se combinam, e o trabalho em call centers associa elementos de rígida exploração e controle de tempos e capacidades com elementos de inclusão social, ao configurar-se em opção considerada satisfatória pelos operadores, na atual conjuntura do mercado de trabalho, pelo fato de: a) não exigir experiência prévia, apenas escolaridade correspondente ao ensino médio completo ou em curso; b) possuir um regime de horários flexível (de quatro, seis ou oito horas), o que possibilita atividades paralelas como estudar ou cuidar dos filhos, por exemplo; c) a remuneração com as comissões (que só são significativas nos primeiros tempos de atividade, pois, após uma média de dois anos, verifica-se uma espécie de exaustão e esgotamento por parte do operador) estão acima do mercado para um regime de menos de oito horas e sem exigência de competências e (ou) formação específica.

Os paradoxos, no entanto, prosseguem. $\mathrm{O}$ teleoperador remete-se hierarquicamente a uma supervisão direta (na maioria dos casos, um teleoperador em progressão de carreira) que, por sua vez, remete-se a uma chefia. O supervisor, para manter-se como tal, necessita atingir metas que devem ser alcançadas pelo conjunto da sua equipe de teleoperadores. Ora, é preciso, assim, um forte controle sobre o trabalho da equipe, de modo a garantir o alcance das metas em tempo real. Durante o atendimento receptivo (quando o operador recebe uma ligação do cliente para reclamações, informações ou compras), há um tempo médio permitido, variável de acordo com a natureza da operação, o que leva o supervisor a gritar para o grupo o tempo médio até o momento, incitandoos a diminuí-lo. Quando se trata de atendimento 
ativo, ou seja, o operador liga para o cliente (como no caso de vendas), o supervisor grita anunciando em que situação o grupo se encontra em relação às metas de venda daquele momento e incita-os a vender "de qualquer jeito" para atingi-las, conforme extrato de entrevista que segue.

Entrou uma senhora do interior, querendo comprar, querendo comprar não, porque ouviu uma propaganda de banda larga na TV, uma senhora de idade assim, aparentava, e ela queria que eu explicasse pra ela o que é que era aquilo. Como que tu vai vender pra uma pessoa que não tem conhecimento, que liga pra pedir informação? Tá entendendo? E difícil. Aí eu expliquei pra ela o que é que era banda larga, como funcionava, porque ela achou que só comprava o modem, conectava e não pagava mais nada. Aí a mulher riu, decerto ela achou que tava muito caro, não ia ter condições, não compensa pra ela. Só que, em vez de ela me falar aquilo, as pessoas têm vergonha de dizer na linha: não, pra mim não vai dar, eu achei que era outra coisa, é muito caro, me desculpa. A maioria não diz isso. A maioria diz: não, eu vou ver com o meu filho, eu vou ver com o meu esposo, eu vou pensar. Têm vergonha de dizer a verdade. E aí quando tem alguém te escutando e a pessoa diz isso, que é que vão dizer de ti: tu não é um bom profissional, tu não conseguiu vender pra ela. Que é que tá acontecendo contigo? E a gestora aquela me escutando. Só que senti que a mulher não ia comprar. Por quê? Ela queria saber o que é que era banda larga, ela achou que era só o modem e conectava. E aí ela [a supervisora] veio pra mim, e isso eu com a cliente na linha: pede um momento. Eu pedi um momento pra cliente, e ela disse: eu tô te ouvindo, não perde essa venda, não quero que tu perca essa venda. E eu: meu Deus do céu, né! Eu vou tentar, eu disse pra ela. Eu já tava aqui, né. E então voltei com a mulher com a maior calma, expliquei... Eu sabia que não ia vender, mas eu tava fazendo o meu papel. Expliquei... Isso e aquilo... A mulher: não, mas eu tenho que ver com o meu filho. E tu sente na pessoa, quando não tinha conhecimento, conforme tu vai explicando... Aí disse pra ela: ah, daí vai ter que comprar o modem, vai pagar provedor, vai pagar operadora, vai dar uns cento e poucos por mês... E aí a mulher, em vez de dizer que não tem condições, não. E a outra foi lá, me escutando: e tu não perde, tu não perde! Uma hora ela pegou e passou ali pelo corredor e eu disse pra ela: tu quer tentar? (operador, 23 anos, 18 meses na ocupação, Brasil).

Se, por um lado, o trabalho possui regras rígidas e controle minucioso, por outro, a fim de atingir as metas, a supervisão passa a ser conivente (passa a "não ver" ou mesmo a incitar de maneira velada) as ações ilícitas que revertem em venda, como, por exemplo, inserir mais itens na venda do que aqueles realmente solicitados pelo cliente.
O problema da reclamação e da reversão só aparece bem depois, ou mesmo passa despercebido para muitos compradores. É um trabalho permeado de injunções paradoxais, um trabalho cuja prescrição não coincide com o trabalho real. A hierarquia é conivente com as infrações, pois são convenientes com as vendas, havendo uma indução à desonestidade. Mas, simultaneamente, observa-se o aumento do controle, para garantir a realização do prescrito e o respeito às regras. A exigência de rendimento é incompatível com o tempo que lhe é consagrado, pois há um aumento constante das metas, de maneira que é preciso trabalhar sempre mais, para garantir o mesmo salário variável. O operador se vê obrigado a unificar e homogeneizar um discurso e uma prática contraditórios.

\section{OS CALL CENTERSNO BRASIL, PORTUGAL ECABO VERDE}

Em Portugal, na cidade de Lisboa, foram feitas onze entrevistas no ano de 2005, numa mesma empresa de call center de atendimento passivo, de prestação de serviços para uma empresa produtora e distribuidora de eletricidade, sendo uma com a gerente de Recursos Humanos e dez com teleoperadores (chamados "atendedores"). ${ }^{6}$

No Brasil, nas cidades de Porto Alegre e Novo Hamburgo (RS), foi feito um total de dezessete entrevistas nos anos de 2005 e 2006, sendo uma delas com uma gerente de Recursos Humanos e dezesseis com teleoperadores de três empresas de call center: seis numa empresa de operação ativa (venda de cartão de crédito), mais dez entrevistas

\footnotetext{
${ }^{6}$ Nota metodológica: é preciso salientar a diferença de qualidade e profundidade entre as entrevistas realizadas dentro da empresa da call center e aquelas realizadas fora dela. As primeiras são entrevistas mais estritas, rápidas e superficiais, enquanto essas últimas permitem a elaboração de um discurso mais personalizado e sincero. Essa diferença se reflete nos extratos de entrevistas que seguem: em Portugal, a totalidade das entrevistas com operadores foi feita dentro da empresa; no Brasil, houve entrevistas dentro e fora; e em Cabo Verde, todas foram feitas fora da empresa (mas não puderam ser gravadas, o que impossibilitou a utilização literal de extratos de entrevistas). As entrevistas com as gerentes de Recursos Humanos foram feitas nas empresas, por ocasião da visita para conhecer as condições e a organização do trabalho.
} 
com operadores que trabalhavam ou haviam trabalhado em duas empresas de call centers (havia sobreposição; por exemplo, um operador que havia trabalhado em duas delas), em diferentes posições (ativo, receptivo), e prestavam serviços para grandes empresas (telecomunicações e provedor internet), para o atendimento de clientes ou vendas ativas (a empresa do setor de telecomunicações possuía seu próprio serviço de atendimento ao cliente por call center). ${ }^{7}$

Em Cabo Verde, na cidade de Praia, foram feitas sete entrevistas no ano de 2007, sendo uma com a gerente de Recursos Humanos e o restante com teleoperadores (chamados "comunicadores"), em uma empresa de call center offshore, que prestava serviço receptivo para uma grande empresa de telecomunicações em Portugal. O serviço prestado era o mais simples dentre todos pesquisados: auxílio à lista telefônica. É o único serviço de call center existente no país e estava em atividade há três anos e meio.

Uma maioria de trabalhadoras mulheres é constatada nos três países. Em Portugal, encontramos teletrabalhadores jovens (predominantes em Cabo Verde), mas também com idade mais elevada (acima dos 30 anos), o mesmo se verificando também no Brasil (ambos com média etária em torno de 25 anos). ${ }^{8}$ Esse dado se reflete igualmente no tempo de trabalho nesse mesmo call center por parte desses operadores portugueses, que chegava a até 12 anos (como operador, sem ascensão para supervisor). Nesse sentido, esses operadores projetam continuidade no trabalho e vislumbram o futuro nessa ocupação, mesmo sem perspectivas de progressão de carreira (ou porque o mercado de trabalho não oferece outras possibilidades, ou porque não possuem competências ou perspectivas de desenvolvê-las com vistas a uma ocupação de maior qualificação). Há baixa rotatividade (em torno de $1 \%$ na empresa pesquisada). As pausas

\footnotetext{
${ }^{7}$ Esses dez teleoperadores foram entrevistados fora de qualquer empresa e foram se indicando um ao outro.

${ }^{8}$ Embora o número de operadores entrevistados não seja significativo para essa descrição do perfil, chamamos a atenção para o fato de esses dados terem sido recolhidos junto às gerentes de Recursos Humanos entrevistadas.
}

durante o horário de trabalho são maiores do que nos outros dois países, e há um bom ambiente e boas condições de trabalho (pouco ruído, boas instalações, comunicação com a supervisão, competitividade, mas com companheirismo). Os operadores portugueses pesquisados são avaliados por número de chamadas, tipo de resolução e tempo médio de chamadas. Osistema de monitoramento da empresa funciona da seguinte forma: são ouvidas três chamadas por mês de cada operador, que não sabe quando está sendo avaliado. Alguns apontaram crer que a empresa ouve mais de três chamadas e seleciona as três "piores", para dificultar a premiação prometida para aqueles com bom rendimento. Os operadores apontam discordância com as avaliações da empresa, e questionam a justificativa, por exemplo, de que o timbre de voz utilizado "não foi o mais simpático". Há uma impossibilidade de se atingirem os objetivos traçados pela empresa, por força do paradoxo intransponível entre o tempo reduzido e a resolução da demanda do cliente. Diante do tempo médio de chamada proposto, a saber, de três minutos e trinta segundos, é preciso "despachar" o cliente, mesmo sem tê-lo atendido corretamente.

Incomoda por causa dos objetivos, dos tempos, não é pelas avaliações. Somos mais penalizados por causa dos tempos. Dependendo, se, por exemplo, eu estou a fazer uma contratação e nos dão um tempo de três minutos e trinta e cinco. Só que aquilo, para um contrato, não se faz em três minutos e trinta e cinco. E se cai muitas chamadas a fazer contratos, este dia você não conta, não consegue concluir aquele tempo de chamada. É aborrecido, porque estamos a ser prejudicados. É muito difícil. Há quem compra, mas a maioria das pessoas provavelmente não compra naquela média. Somos prejudicados a nível dos prêmios. Mas isso é como tudo, né? Tem objetivos, mas não conseguimos cumprir (operadora, 31 anos, três anos na ocupação, Portugal).

O tempo reduzido e a busca pelos prêmios de produtividade é fonte de stress, pela impossibilidade de combinar essas metas:

Se bem que, acho que para trabalhar aqui tem que se adotar um esquema. A pessoa, não pode ser uma pessoa limitada. Uma pessoa limitada não consegue trabalhar aqui. (...) Sabe que há pessoas que se contradizem..., conseguem traba- 
lhar aqui sem se chatear muito, sem ligar para o que o cliente diz, "sim, a senhora tem toda a razão", mantendo a calma com cliente, não se exalta, mas, ao mesmo tempo, para ele manter esta calma, vai contradizer o tempo médio de chamada, vai alongar o tempo médio de chamada. Agora existem duas situações. Se eu me preocupo com o tempo médio de chamada, com aquilo que eu vou ganhar, eu não posso manter essa calma, logo vou me estressar mais. Mas se eu estou despreocupado com aquilo, eu vou manter essa calma e pronto. Aí já não vou cumprir os meus tempos, vai ficar para depois, eu vou ficar para depois, porque não vou ganhar tanto (operador, 23 anos, três anos na ocupação, Portugal).

Pelo fato de alguns operadores trabalharem nessa ocupação e na mesma empresa há muito tempo, é possível vislumbrar mudanças no trabalho a ser executado,

Eu gostava de ter contato com o cliente; faz diferença, aquela parte humana que na altura não tinha nada a ver com isto aqui agora. Nós temos tempos, é diferente, não é tão humano. Aqui é quantidade. Chamadas no menor tempo possível, enquanto naquela altura o call center abrangia só uma parte do país, era só uma parte pequenina, era uma parte mais interior, naquela altura não havia tempo. O que interessava ali era a comunidade, o cliente tinha que se sentir uma pessoa, bem atendida, com muita simpatia. $\mathrm{O}$ nosso trabalho ali era essencialmente comunicar-nos com simpatia, era a maneira de cativarmos o cliente. E era X [nome da empresa de eletricidade] também. Na altura [há 12 anos], éramos muito poucos a atender. Sempre brigávamos para atender às chamadas, porque havia poucas chamadas pelos clientes. Hoje não, é muito stress. Havia poucas chamadas e também poucos clientes. Havia também, não sei, uma interligação entre os colegas mais forte. Todos nos conhecíamos, agora não mais nos conhecemos, não é? Era diferente, na altura. Na altura, nós dizíamos aquilo era um emprego, agora é um trabalho, é uma maneira de viver, não é? Nós, os colegas, nos sentíamos mais ligados porque éramos pouquíssimos, éramos muito poucos. Então, dava para dar, entre uma chamada e outra, uma pousadinha. Agora não dá (operadora, 33 anos, 12 de ocupação, Portugal).

Não ter um "emprego", mas um "trabalho", é um dado que remete à exigência de mobilização subjetiva, de implicação no trabalho. Não basta ir trabalhar, trata-se de "uma maneira de vida": cadenciada, sem pausas, sem cooperação entre os pares, mas "com sorriso na voz".

Em Portugal, predomina o que denominamos a dimensão compulsória do trabalho em call centers (identificada na totalidade dos entrevista- dos). O operador se investe no trabalho, mas experimenta a ausência de opções: ou por não estar cursando uma faculdade e (ou) buscando outra perspectiva de trabalho, ou por não vislumbrar a possibilidade de desenvolver outras competências. O contexto de inserção no mercado de trabalho é de possibilidades reduzidas. Há desesperança e conformismo: dispor (e manter) de emprego assalariado é o objetivo primordial.

É assim, nós estamos numa altura em que não vale a pena pensar (pausa), pensar em outro tipo de profissão; assim, nós não temos muitas perspectivas. Hoje tem tantas pessoas desempregadas, mais uma empresa que fechou, mais não sei quê. E eu dou graças a Deus, graças a Deus por ter um emprego, um trabalho, que até gosto. Porque às vezes é horrível, eu chego a casa em um stress, sabe? Mas penso, no fim até gosto, até gosto daquilo (operadora, 33 anos, 12 de ocupação, Portugal).

No Brasil, no seio das empresas estudadas, há uma maioria jovem e estudante. O trabalho em call centers é muito procurado pela flexibilidade de horários e pela possibilidade de estudar simultaneamente, além de não haver exigências de qualificação e (ou) experiência prévia. A rotatividade é muito alta, e a pressão por produtividade também. O tempo máximo de emprego encontrado numa mesma empresa foi de quatro anos (um entrevistado trabalha no telemarketing há 11 anos, mas apenas há um ano na empresa em que se encontrava). A maioria dos entrevistados vivencia sua ocupação em call centers como um emprego trampolim, o que evidencia uma dimensão provisória desse tipo de trabalho, ou seja, trata-se de um emprego de passagem. O investimento pessoal repousa sobre as perspectivas profissionais futuras. O trabalho em call center é um trampolim, pois é uma maneira de viabilizar financeiramente objetivos futuros mais "nobres", como se formar e trabalhar na área de formação, o que propicia uma relação instrumental com o trabalho.

É, comparando-se as condições atuais, que a maioria dos jovens está desempregada, ganhando pouco, levando em conta também que não era um trabalho de peso, digamos assim, em que tu passa o dia inteiro dentro da fábrica e vai ganhar aquilo pro resto da vida, era mais o tipo do em- 
prego em que tu vai pra trabalhar por um tempo e depois sair pra outra coisa, entende. E o dinheiro tá me servindo. E, apesar de ser muito puxado, seis horas é um bom período de trabalho. Com a contrapartida de ter que trabalhar aos finais de semana, claro, mas, é bom, porque eu trabalho seis horas (operador, 23 anos, três anos na ocupação, Brasil).

Embora a dimensão provisória do trabalho seja predominante, verificou-se secundariamente, entre os teletrabalhadores entrevistados, uma dimensão precária do trabalho em call centers. Não há projeção profissional futura nem de carreira, pois os operadores não desejam permanecer trabalhando em call centers, mas vão levando e se adaptando. A dimensão provisória, entre aqueles que vislumbram uma alternativa fora dos call centers, mas que não se concretiza ao longo do tempo, pode se transformar em dimensão de precariedade: mesmo em condições insatisfatórias, os teletrabalhadores permanecem no emprego. Se lhes surgisse outra oportunidade, abandonariam essa ocupação, mas, na ausência dessa alternativa de emprego, não só prosseguem na ocupação como também vislumbram procurar outro posto de trabalho em outra empresa de call center, no caso de demissão. Se não se pode falar em precariedade no sentido de ausência ou redução de direitos e garantias do trabalho, pode-se falar de precarização da qualidade no exercício do trabalho. ${ }^{9}$ Verifica-se uma associação dos sentimentos de insegurança e adaptabilidade. $\mathrm{O}$ atendimento de tele marketing é um trabalho que se esgota e esgota o trabalhador, o trabalhador possui "prazo de validade". A precariedade decorre da necessária e constante rotatividade de empregos, da insegurança, da provisoriedade, da falta de melhores opções e dos custos psíquicos do trabalho.

Angústia, vontade de chorar... Eu chegava na operação e já entrava já chorando, aí às vezes me perguntavam: alguém te fez alguma coisa? E eu assim: não, ninguém me fez nada, me deu vontade de chorar. Aí eu chegava, digamos, muitas

\footnotetext{
${ }^{9}$ Os termos precariedade e precarização são utilizados aqui como sinônimos, a despeito do intenso debate conceitual em torno desses termos. A precariedade seria uma condição já instalada, enquanto a precarização remete ao processo de tornar-se precário.
}

vezes, acho que uma ou duas vezes por semana, nos últimos tempos, eu chegava chorando na operação. Era só descer do elevador e me dava ataque de choro (operadora, 27 anos, três anos na ocupação, Brasil).

Frente à falta de opções para trabalhadores de baixa qualificação e escolaridade correspondente ao ensino médio, o trabalho em call center pode se tornar uma opção de mais longo prazo, mesmo que originalmente fosse apenas um primeiro emprego e (ou) uma alternativa ao desemprego.

Muitos entram no desespero, e não é o que a pessoa procura. O telemarketing hoje pode ser um quebra-galho, como pode ser uma coisa que te possa fazer ter uma subida na tua carreira (operador, 30 anos, 11 na ocupação, Brasil).

\section{O paradoxo do trabalho em call center pode} ser percebido de maneira concreta nos dois extratos de entrevista que seguem: o primeiro que explicita as vantagens de tal trabalho e o segundo, as suas desvantagens.

O tempo que ele [o trabalho] dura, seis horas. Todos os outros eram mais longos. É, porque eram nove horas, dez horas de trabalho. Então, ele tem coisas legais, porque, por exemplo, assim, tu exercita muito aquele raciocínio de controlar e já reverter a objeção, porque tem que pensar muito rápido. A pessoa te apresenta uma objeção e tu já tem que largar outra de volta, e aí o cliente fala sobre um provedor que todo mundo disse que era melhor, já tem que acessar a página do provedor, ver o que é que tem lá escrito, e já contrapor, argumentar com ele, contrapor com a nossa oferta em relação a ele. Tem as amizades, também, que eu conheci muita gente diferente, tudo quanto é tipo de gente que trabalha lá. O pessoal geralmente é bem alegre, porque é tudo gurizada, gente da faixa etária de vinte a trinta anos (operadora, 34 anos, quatro anos na ocupação, Brasil).

As cinco mais importantes, negativas. Primeiro: tu deixa de ser um ser humano, tu passa a ser a voz do outro lado da linha. Algumas pessoas pensam que é até gravação. Isso é sério. Entra o atendente e tem gente que ainda pensa que tá falando com uma gravação. A segunda: o trabalho é escravo. Uma vez eu falei: só falta ter uma bola de ferro amarrada no nosso pé pra controlar aonde a gente vai. Só que daí eu parei pra pensar, essa bola já existe. Tá na nossa cabeça, chama-se head set. (...) Imagina, eles tentam regular cada segundo, até de uma necessidade fisiológica do funcionário. E além de querer regular cada segundo da necessidade fisiológica, ou seja: oh, você só pode ir ao banheiro quatro minutos e cinqüenta e nove segundos! Além de querer regular o tempo, eles querem regular o horário também. Tipo 
assim: não, você não pode ir agora às dez para as sete no banheiro, você tem que esperar mais trinta segundos, quando vão ser dez pras sete e trinta segundos, você não pode ir agora, você tem que esperar! Esse tipo de controle é escravidão, não tem outro nome. Outra coisa negativa, apesar de ser seis horas por dia, essas seis horas é praticamente corrido. Eles dão intervalo que eles dizem de quinze minutos, o que é mentira, é quatorze e cinqüenta e nove, porque se tu volta nos quinze, o teu tempo já fica vermelho no sistema, e já é o suficiente pra tu perder alguma coisa. Então, essas seis horas, quase corridas, seis dias por semana. Então, quando chega no domingo, só resta, restam duas coisas pra fazer: no começo, quando tudo é novo, é ficar alugando as outras pessoas explicando como é o telemarketing e o que é que tu faz, e no final, quando tu já tá pensando em amarrar o head set no pescoço e se jogar pela janela, é chegar no sábado em casa, entrar, não falar com ninguém, só levantar no domingo lá pelo meio da tarde, tomar um banho, voltar a se deitar e ficar pensando: meu Deus do céu, amanhã já é segunda! Eu não descansei nada. A outra coisa também extremamente negativa pra mim é a remuneração. Quem não conhece, fala: ah, mas o quê, tu ganha tudo isso pra trabalhar sentado, na frente dum computador, seis horinhas por dia? A gente merecia ganhar muito mais. Porque tu te doa de corpo e alma pra um trabalho e eu duvido muito que alguém entre pro telemarketing e pense assim: ah, é isso que eu quero pro resto da minha vida, esse trabalho me enobrece. Duvido! As pessoas tão ali pela mesma forma que eu tava, porque precisam trabalhar. (...) Tu te conforma. Fazer o quê? (operador, 24 anos, quatro anos na ocupação, Brasil).

Em Cabo Verde, a ampla maioria era de teletrabalhadores jovens (e mulheres, como já mencionado), mas não estudantes. A empresa havia se instalado há pouco mais de três anos e, portanto, os que possuíam a maior experiência em teleatendimento eram aqueles que haviam sido contratados desde o início das operações. A empresa portuguesa de telecomunicações "encomendou" uma empresa de call center para o atendimento mais simples e de menos exigência, chamado atendimento informático, do tipo "auxílio à lista telefônica”. Cabo Verde foi escolhido como sede, por ser o país cuja pronúncia (o sotaque) do português mais se aproximava da de Portugal, além dos bons índices de escolaridade da população e, evidentemente, os baixos salários. Os teletrabalhadores foram e são escolhidos (em torno de 200 trabalhadores) pelo domínio prévio da língua. No entanto, após a seleção, eles passam um período de formação, dedicado a aprender as tarefas, mas também aprimorar o português e aproximá-lo ao máximo daquele que é falado em Portugal. A fim de atingir esse objetivo, são proibidos de falar em crioulo (língua mais popular do país, mas considerada "inculta") nas dependências da empresa, mesmo em situações de pausa do trabalho. Os principais objetivos da empresa, no momento, são trazer outros serviços mais complexos, especialmente o telemarketing, reduzir o tempo despendido nas chamadas e o turn over (no início das atividades, chegava a $12 \%$; hoje, ainda alguns saem mas voltam, porque não conseguem emprego melhor). Os contratos são por tempo determinado, por um período de seis meses, podendo ou não ser renovados, o que significa não haver demissões no sentido estrito do termo.

Os "comunicadores" recebem prêmios por: a) produtividade quantitativa, ou seja, tempo de chamada, tempo de log in, pausas; b) qualitativa, ou seja, chamadas teste, auditorias e avaliação de três competências, a saber, gestão da mudança (adaptação a situações novas), rigor e responsabilização (reclamações), desenvolvimento pessoal e profissional (e-learning, formação contínua, integração à comunidade), c) assiduidade; d) pontualidade.

Apesar de se constituir numa tarefa simples (informar pelo automático o número de telefone solicitado), é preciso estabelecer uma relação com o cliente ou usuário, a fim de traduzir sua demanda, como, por exemplo, quando o cliente pede um número de telefone indicando o sobrenome e bairro onde reside, o teleoperador identifica cinco números com essas características, sendo, então, necessário fazer outras perguntas para refinar a pesquisa, até chegar ao número demandado. É preciso, pois, conhecer as regiões de Portugal, os bairros das cidades, estabelecer a comunicação e o acesso a informações, enfim, absorver a cultura do país. A cultura portuguesa é absorvida igualmente pela importância do domínio da língua falada em Portugal, uma vez que eles não podem ser identificados como caboverdianos. Eles relatam que, muitas vezes, os clientes desconfiam e perguntam se estão sendo atendidos por um ne- 
gro, pergunta que eles não podem, de maneira nenhuma, responder, devendo tergiversar, voltar à demanda específica do cliente, pois não podem ser identificados. Muitos clientes, ao perceberem que não estão sendo atendidos por portugueses, mas por estrangeiros (às vezes, inclusive, confundem com brasileiros), se ofendem e desligam: "Isto é culpa do governo português, ser atendido por um preto". A exploração, por parte de um país colonizador, de um trabalhador que não pode ter identidade é chamada, pelos operadores caboverdianos, de "colonização moderna" ou "escravatura moderna", sendo que anunciam que "a escravidão não terminou”. Enquanto, para alguns, essa é mais uma forma de colonização, um teleoperador justificou sua tolerância em relação a trabalhar para Portugal nessas condições por ser jovem e não ter vivenciado a independência (apesar de recente, pois se deu no ano de 1975): "somos uma gente que não viveu a colonização e a independência, não temos sentimentos quanto a isso", segundo suas palavras.

Além de serem proibidos de falar em crioulo com os pares ou com os clientes, são também proibidos de buscar emprego na filial da empresa, que se localiza em Coimbra. Lá não há teleoperadores negros, enquanto que, em Cabo Verde, não há brancos, exceção feita à gerência e à supervisão. É exigida e constantemente testada a negação da própria língua (pelo menos a mais falada) da sua origem e da sua identidade como cidadão de um país. Mesmo que o cliente só entenda crioulo (como um caboverdiano que se encontra em Portugal), não podem responder em crioulo e serem identificados. Há algumas formas para tentar burlar a proibição: nesses casos, o cliente pergunta em crioulo, e o operador fornece o número de telefone solicitado pelo automático; assim, ele nada disse em crioulo, mas a comunicação se deu em crioulo. Há também “chamadas-teste”, realizadas pela supervisão que, sem se identificar como tal, faz alguma provocação para que respondam em crioulo.

A pressão do trabalho é seguidamente apontada pelos operadores ("o trabalho acaba com o psíquico das pessoas"), mas a conquista do português "correto" significa um ganho social e um trampolim para ascender a um status e a reconhecimento superiores. Falar corretamente o português e vencer o sotaque caboverdiano (o "pretoguês") reveste-se de valor social e simbólico. Falar "um bom" português é ascender a um outro patamar de reconhecimento social. Relatam que passaram a ser mais bem tratados nas lojas e repartições públicas, sendo que há uma escala decrescente de reconhecimento quanto ao uso da língua: primeiro, falar bom português; segundo, falar mal português; e terceiro, falar em crioulo.

Foi possível verificar, tal qual entre os teleoperadores brasileiros, a dimensão provisória e a dimensão precária do trabalho. A dimensão provisória revela-se na perspectiva do emprego em call center servir de trampolim para uma vida profissional futura mais satisfatória. O domínio da língua portuguesa, por si só, significa acesso a novos patamares sociais, de reconhecimento e inserção social, e a remuneração, em muitos casos, tem por finalidade financiar os estudos, mesmo que seja num futuro próximo, e estudar significa a perspectiva de melhores ocupações no mercado de trabalho. Para aqueles que não apresentam uma tão exitosa adaptação ao trabalho, sua dimensão precária, por sua vez, revela-se na dificuldade de alcançar um domínio perfeito da língua portuguesa e da informática, correndo, assim, o risco de não terem seus contratos renovados e não obterem uma outra colocação de igual nível de exigência e remuneração.

Em resumo, em Portugal, constatamos, entre os teleoperadores entrevistados, de maneira predominante, a experiência da obrigatoriedade daquele trabalho e a impossibilidade de qualquer outro. O sentimento dominante é de perda e de falta de perspectivas ou alternativas. Num contexto de enxugamento do mercado de trabalho, os "atendedores" vislumbram uma possibilidade de emprego de mais longo prazo nos call centers. Mas não experimentam a insegurança e a precariedade, pois há certa segurança na continuidade e na manutenção de condições de trabalho existentes. No 
Brasil e no Cabo Verde, encontramos uma população de teleoperadores ou projetada no futuro (marcada pela provisoriedade da situação de trabalho, uma vez que o investimento pessoal encontra-se nas atividades paralelas, possibilitadas pelo regime de trabalho de seis horas, como cursar uma faculdade, ou criar os filhos), ou imersa na fragilidade do presente (marcada pela precariedade e pela insegurança, ou seja, diante da falta de opções concretas e satisfatórias no mercado de trabalho, o anseio é de manter o emprego, mas a vivência é de insegurança e adaptação a "qualquer" pressão ou condição para a manutenção do posto de trabalho).

Há similaridades importantes nos três países: os teleoperadores são impelidos a se doarem ao trabalho, assim como se adaptarem contínua e infinitamente às exigências de produtividade, que se renovam de maneira incessante. Os sujeitos necessitam traçar estratégias de inserção individual na situação de trabalho que tenham êxito, ou para manter o emprego, ou para lograr defender-se da pressão, da cadência e do nível de exigência de envolvimento pessoal no trabalho. Mas essas estratégias, mesmo quando são bem sucedidas, representam custos pessoais aos trabalhadores, ou seja, há ganhos, mas é preciso pagar um preço. Essa associação entre escolhas individuais de inserção no trabalho - face a uma situação coletiva e previamente determinada pela própria organização do trabalho - e custos objetivos e subjetivos desemboca em variadas vivências do trabalho. E são essas vivências que esse trabalhador teve de apreender. A vivência do trabalho em call centers desemboca em uma fragilidade identitária, no enfraquecimento simbólico da relação com o trabalho e com aquilo que, no trabalho, se traduz em construção identitária. Sem reconhecer e ter reconhecida a importância e a utilidade do seu trabalho (é preciso enganar, convencer, "empurrar" um produto, invadir as vidas pessoais dos clientes, dispensá-los rapidamente sem ter resolvido seu problema ou respondido à sua demanda), os teleoperadores não vislumbram uma contribuição social possível para o seu trabalho, o que seria capaz de lhe conferir um sentido e efetuar um "re- torno" para o sujeito que trabalha em termos de realização de si. No entanto, paradoxalmente, é preciso se doar e investir por inteiro no trabalho.

A coleta de dados em três diferentes países de língua portuguesa acrescentou à vivência no trabalho elementos de determinação sociocultural. Dito diferentemente: se, por um lado, a vivência no trabalho é reveladora das condições sociais de sua produção, por outro, elementos de ordem social e cultural revelam determinações da história e da constituição socioeconômica de cada um dos países. Brasil e Cabo Verde são países marcados pelas desigualdades econômicas e sociais, pelos desequilíbrios regionais, pela concentração de riquezas, pela saúde e educação aquém das necessidades da população, pelo desrespeito aos direitos sociais. Para operadores brasileiros e caboverdianos, trabalhar sob a segurança de um contrato formal de trabalho representa ganhos importantes. O que não quer dizer que não haja perdas: o risco de não lograr manter o emprego torna o sentimento de perda imanente à própria situação de trabalho. Já Portugal insere-se no contexto da Europa e, portanto, mesmo sendo um "irmão pobre", se comparado aos principais países europeus, conheceu importante crescimento econômico após seu ingresso na União Européia, além de ter sido importante país colonial, do qual Cabo Verde se tornou independente há apenas trinta e dois anos. Os direitos sociais são assegurados, e as desigualdades econômicas são mais atenuadas, se comparadas àquelas encontradas no Brasil e em Cabo Verde. $\mathrm{O}$ sentimento dominante entre os teletrabalhadores portugueses é de falta de opções, mas não propriamente de precariedade ou provisoriedade. Eles podem manter-se nessa situação, que não é a ideal, mas que lhes garante certa segurança.

\section{CONCLUSÃO: os paradoxos do trabalho em call centers}

A demanda de mobilização subjetiva, de autonomia no trabalho, de disponibilização de competências comunicacionais e relacionais sig- 
nifica, teoricamente, o enriquecimento da natureza e do conteúdo do trabalho. Pode-se, pois, aqui, traçar um paralelo com os avanços morais do capitalismo, em termos de normas e valores, explicitados por Honneth (2006). Seguindo o autor, é possível demonstrar o paradoxo que esse avanço engendra, na medida em que ele se reverte de um caráter normativo. É exigido, cobrado, demandado ao teletrabalhador doar-se ao trabalho e, ao mesmo tempo, a tudo se sujeitar. O avanço moral se reverte em sujeição pessoal, e, no caso específico do trabalho, o engajamento se associa à provisoriedade, à precariedade ou à obrigatoriedade.

E não se trata de uma simples sujeição: ela é total na situação de trabalho, podendo estenderse às demais dimensões da vida, como os vários casos relatados de depressão e suicídio.

Fiquei sabendo no dia seguinte, porque eu acho que ele se matou num sábado e eu fui trabalhar no domingo, alguma coisa assim, e tava todo mundo falando daquilo. Mas o que a gente sabe, da "rádio corredor", como a gente chama, que é de onde as notícias surgem, é que ele tava tendo relação difícil com o supervisor dele. Acontece às vezes de um supervisor resolver te odiar loucamente, e daí começa a pegar no teu pé por tudo. Então, era o caso dele. Até tem um grupo de gente que tá tentando bater nesse supervisor por causa disso. E o supervisor tava dificultando a vida dele um pouco lá, criando umas situações que eram mais complicadas pra ele, colocava ele em coisas xaropes, e tudo mais. E ele era uma pessoa que tinha problema de depressão, um cara de vinte e dois anos, era uma pessoa bem nova. E ele entrou no prédio, entrou no oitavo andar, que é uma sacada ao ar livre, dizendo que não agüentava mais essa angústia... E aí ele começou a esbravejar, aí ele ligou pra ex-supervisora dele, não sei se ele ligou pra falar do que tava acontecendo, ninguém sabe o que ele falou pra ela, porque ela não falou. E ele disse: não, não agüento mais, não sei o que lá, desligou o telefone, largou a mochila no chão e pulou. E ficou todo mundo pasmo... (operadora, 34 anos, quatro anos na ocupação, Brasil).

O paradoxo se revela na combinação das esferas do progresso moral com a sujeição que engendra o seu contrário: 1) o individualismo, entendido como autonomia e autenticidade, revertese em implicação pessoal, não como fonte de realização de si e enobrecimento humano, mas como norma a ser seguida, o que reverte em ser desapossado de si, pois refém da lógica instru- mental; 2) a extensão de direitos e formas de participação, entendida como maior autonomia individual, reverteu em maior responsabilização de si e enfraquecimento das responsabilidades sociais, inclusive do Estado, de maneira que o emprego, o trabalho e o êxito na vida profissional passaram a ser de gerência e responsabilidade única dos sujeitos; 3) a noção de performance, como contribuição, como capacidade de participar de maneira igualitária na construção do todo social, reverte em insegurança quanto ao real valor do trabalho, permeado de injunções paradoxais. A contribuição é pessoal e subjetiva, mas unicamente adquire valor quando instrumentalizada. ${ }^{10}$

Poder inferir sobre o trabalho de uma maneira generalizante, a partir da experiência de três países, já significa, por si só, afirmar que o trabalho informacional está perdendo traços culturais, embora se diferencie por determinações socioeconômicas. Os paradoxos a que os teletrabalhadores estão submetidos parecem ser os mesmos, apesar de apresentarem dimensões próprias a cada país. No que se refere ao trabalho em call centers, em Portugal sobressai a dimensão compulsória do trabalho; no Brasil e em Cabo Verde, é a provisoriedade e a precariedade que caracterizam a vivência nesse trabalho. Ora, em todos os três países, vê-se a falta de opções, a subordinação e a impotência associarem-se a um discurso de emancipação pelo trabalho, que logra mobilizar o sujeito que trabalha. A impossibilidade de conciliar autonomia e sujeição, de transpor o paradoxo, torna o capitalismo incapaz de fazer do trabalho uma fonte satisfatória de construção da identidade, de elo social, ou de elemento capaz de fortalecer ações coletivas.

(Recebido para publicação em setembro de 2007) (Aceito em novembro de 2007)

${ }^{10}$ Das quatro esferas do progresso moral apresentadas por Honneth, apenas a esfera do amor, neste estudo, não foi explorada na sua relação com o trabalho. Lembramos, no entanto, que o amor "puro" sofre os efeitos de um trabalho que transborda para a vida privada. 


\section{REFERÊNCIAS}

BAIN, P.; TAYLOR, P. Entrapped by the 'electronic panopticon'? Worker resistance in the call centre. New Technology, Work and Employment. London, Blackwell Publishers. v.15, n.1, 2000.

BOLTANSKI, L.; CHIAPELLO, E. Le nouvel esprit du capitalisme. Paris: Gallimard, 1999.

EHRENBERG, A. L'individu incertain. Paris: Calman-Lévy, 1995.

FRASER, N. Da redistribuição ao reconhecimento? Dilemas da justiça na era pós-socialista. In: SOUZA, J. (Org.) Democracia hoje: novos desafios para a teoria democrática contemporânea. Brasília: UnB, 2001. p.245-282.

; HONNETH, A. Redistribution or recognition: a political-philosophical exchange. London: Verso, 2003b.

GORZ, A. Métamorphoses du travail et quête de sens. Paris: Galilée, 1988.

HONNETH, A. Luta por reconhecimento; a gramática social dos conflitos sociais. São Paulo: Editora 34, 2003a.

; FRASER, N. Redistribution or recognition: a politicalphilosophical exchange. London: Verso, 2003.

. La société du mépris: vers une nouvelle théorie critique. Paris: La Découverte, 2006.
PALMADE, J. Communication paradoxale et imaginaire consensuel. In: SFEZ, L. (Org.) Encyclopédie et Dictionnaire critique de la communication. Paris: PUF, 1993.

PERRET, B. Fin de la valeur travail? Esprit, Paris, n.1, 1988.

ROSENFIELD, C. L'autonomie comme norme et le rapport au travail; une étude comparative France-Brésil. Lille: ANRT, 2003.

. Autonomia outorgada e apropriação do trabalho. Revista Sociologias, Porto Alegre, IFCH/UFRGS, v. 6, n.12, p.202-207, jul./dez., 2004..

Construcão da identidade no trabalho em call centers: a identidade provisória. In: ANTUNES, R.; BRAGA, R. (Orgs.) Ciberproletários. São Paulo: Boitempo, 2008. No prelo

SAAVEDRA, G. A teoria crítica de Axel Honneth. In: SOUZA, J.; MATTOS, P. A teoria crítica no século XXI. São Paulo: Anna Blume, 2007.

TAYLOR, C. As fontes de self; a construção da identidade moderna. São Paulo: Loyola, 1997.

ZARIFIAN, P. Sur les centres d'appels (éléments intégrés dans l'introduction du n.114 de la Revue Réseaux, oct.2002). Disponível <http://perso.wanadoo.fr/ philippe.zarifian/page52.htm> Acesso em: 22 dez., 2006. 


\section{PARADOXOS DO CAPITALISMOF TRABALHO EM CALL CENTERS: Brasil, Portugal e Cabo Verde}

Cinara L. Rosenfield

O objetivo deste artigo é compreender o contexto do trabalho na chamada sociedade da informação e as diferentes formas de trabalho que nela se desenvolvem, em especial o teletrabalho em call centers. Diante de um novo paradigma tecnológico, característico da era da informação, trata-se de analisar as diferentes configurações do trabalho. O trabalho em call centers parece condensar as ambigüidades de um trabalho informacional com alto controle, o que o colocaria entre as esperanças do póstaylorismo e os temores do neo-taylorismo. A Teoria Crítica de Axel Honneth permitenos pensar a experiência do trabalho no seio daquilo que o autor intitula "paradoxos do capitalismo". O significado do trabalho, em sua dimensão social, ganha força ao ser demonstrado que o "novo capitalismo" logra produzir progresso moral, baseado nos legados do Estado Social e do modelo taylorista e fordista de trabalho, e, simultaneamente, produz o seu contrário, ao erodir o alcance emancipador dessas normas e valores. Este estudo analisa o trabalho em call centers em três países de língua portuguesa: Brasil, Portugal e Cabo Verde.

\section{PARADOXES OF CAPITALISM AND WORK IN CALL CENTERS: Brazil, Portugal and Cape Verde}

Cinara L. Rosenfield

The objective of this paper is to understand the context of labor in the socalled information society and the different work forms that grow in it, especially the long distance work in call centers. Facing a new technological paradigm, characteristic of the information era, the different

The work in call centers seems to condense the ambiguities of a informaional job with high control, what would put it among the hopes of the post-taylorism and the fears of the neo-taylorism. Axel Honneth's Critical Theory allows us to think of the experience of the work in the midst of what he entitles "paradoxes of the capitalism".The meaning of labor, in its social dimension, gains force when it is shown that the "new capitalism" achieves to produce moral progress, based on the legacies of the Social State and of the taylorist model and fordist labor, and, simultaneously, produces its opposite, by eroding the emancipatory reach of those norms and values. This study analyzes the work in call centers in three Portuguese language countries: Brazil, Portugal and Cape Verde.

Palavras-chave: paradoxos do capitalismo, trabalho informacional, call centers, mobilização subjetiva no trabalho e lógica instrumental.

KEYworDs: paradoxes of the capitalism, informational work, call centers, subjective mobilization in labor and instrumental

\section{PARADOXES DU CAPITALISME ET DU TRAVAIL DANS LES CALL CENTERS Brésil, Portugal et Cap Vert}

Cinara L. Rosenfield

Cet article se propose d'analyser le contexte du travail dans la société dite de 'information et les différentes formes de travail qui se développent en son sein, tout pécialement le télétravail dans les call centers. Face à ce nouveau modèle technologique, caractéristique de l'ère de l'information, il s'agit d'analyser les différentes configurations du travail. Le travail dans les call centers semble représenter à lui seul les ambiguïtés d'un travail informationnel extrêmement contrôlé, ce qui le placerait entre les espoirs du posttaylorisme et les peurs du néo-taylorisme. La Théorie Critique de Axel Honneth nous permet de penser l'expérience de travail au cœur de ce que l'auteur appelle les “paradoxes du capitalisme”. Le sens du travail, dans sa dimension sociale, acquiert une certaine force orsque l'on montre que le "nouveau capitalisme” cherche à produire un progrès moral basé sur l'héritage de l'Etat Social et du modèle tayloriste et fordiste du travail. Simultanément il produit son contraire, par l'érosion de sa dimension émancipatrice de ces normes et de ces valeurs. Cette étude analyse le travail dans les call centers de trois pays de langue portugaise: le Brésil, le Portugal et le Cap Vert.

Mots-Clés: paradoxes du capitalisme, travail informationnel, call centers, mobilisation subjective dans le travail et logique instrumentale. 